\title{
¿Qué he hecho yo para merecer esto? \\ (O cómo acabé en Postmodernos Anónimos): La percepción de la postmodernidad en la prensa española
}

\author{
Manuel Almagro Jiménez \\ Universidad de Sevilla
}

\begin{abstract}
"Me aburro, me aburro, me he saturado de lo postmoderno, no puedo con ello" (C+ 22/4/99). ${ }^{1}$ Esto, que podría ser el sentimiento de muchos de nosotros al final de este II Seminario sobre Postmodernismo, es lo que expresa Pedro Almodóvar, uno de los mayores instauradores de "lo postmoderno" (como él mismo dice), y alguien que ha usado como tema en su cine "el aroma de la postmodernidad" (M 12/4/98), al comentar su adiós a una etapa y la apertura de una nueva fase estética con Carne Trémula. Este comentario de Almodóvar podemos relacionarlo con las alusiones aquí y allá del novelista Antonio Muñoz Molina, quien, en sus artículos de prensa, casi siempre que algo va mal acaba acusando a la postmodernidad. Un caso aún más notable es el de Mario Vargas Llosa, quien tras un extenso artículo sobre la frivolidad del postmodernismo (P 27/3/94), se superó a sí mismo en un artículo significativamente titulado "La hora de los charlatanes" (P 24/8/97). En él cuenta que fue a escuchar una conferencia de Jean Baudrillard, al que le unía una antigua amistad de cuando ambos eran de izquierdas. Mientras espera hasta la hora de la conferencia entra en la librería del Institute of Contemporary Arts y descubre con "mayúscula sorpresa" que en sus estanterías "las anticuadas secciones de antaño-literatura, filosofía, arte, cine, crítica" habían sido reemplazadas por "las postmodernas de teoría cultural, clase y género, raza y cultura, y un estante titulado 'el sujeto sexual."' La sorpresa continúa con la conferencia misma: Vargas Llosa critica que Baudrillard comenzara citando Jurassic Park, que continuara con "pases mágicos" exponiendo su teoría sobre el simulacro, y, en definitiva, que hubiera evolucionado en sus ideas. Lo más sorprendente de todo es la reacción final de Vargas Llosa en lo que al fin y al cabo no deja de ser un debate intelectual: "Al terminar la conferencia, no me acerqué a saludarlo ni a recordarle los tiempos idos de nuestra juventud, cuando las ideas y los libros nos exaltaban y él aún creía que existíamos."
\end{abstract}

Sin duda, las alusiones en los artículos de Muñoz Molina y en los de Vargas Llosa transmiten inequívoca e indefectiblemente, además de frivolidad, un aire de pecaminosidad en este objeto de estudio y un cierto deseo de prohibición que, como se puede suponer, no hizo sino acrecentar mi curiosidad. Imaginaba a una supuesta deidad del postmodernismo preguntando: "Y vosotros, ¿quién decís que soy yo?" Y para contestar a esta pregunta el método parecía ofrecérnoslo el mismísimo J. L. Borges: "La Universidad debiera insistir-

\footnotetext{
${ }^{1}$ Entre paréntesis se ofrece la fecha de publicación de los textos utilizados y citados, que viene precedida por la inicial del periódico o del medio referido; así, A: ABC; M: El Mundo; P: El País; V: La Vanguardia; C+: Canal+.
} 
nos en lo antiguo y en lo ajeno. Si insiste en lo propio y lo contemporáneo, la Universidad es inútil, porque está cumpliendo una función que ya cumple la prensa" (P 22/6/99). Así pues, decidí averiguar qué podría haber de verdad en la opinión de Borges, pues sin duda el periódico, en cuanto forma y vehículo de representación, es un ejemplo de cómo se percibe, cristaliza y, finalmente, se institucionaliza una determinada manifestación cultural.

En primer lugar hay que decir que, según la prensa, son pocos los gurús reconocidos de la postmodernidad, aquellos que inicialmente nos la definieron. Se habla de "Lyotard, teórico que definió el postmodernismo" (M 22/4/98), de Baudrillard, "gran teórico de la postmodernidad" (P 28/9/99), de "Lipovetsky . . . que en su día ya nos definió el postmodernismo" (V 20/1/99), o de "estudiosos de la postmodernidad como [entre otros] Vattimo" (P 15/9/99). Son "los teóricos de la postmodernidad," quienes "sostienen que toda la metafísica occidental deșde Platón descansa en el principio de identidad: $\mathrm{A}=\mathrm{A}$ " (P 30/8/99). El problema es que "la discusión sobre qué es la postmodernidad . . . es un debate irritante ... en el sentido de que cada opinión [parece] simplificar la del contrario" (M 27/3/98).

Lo que sí parece ser cierto es que, por usar términos al uso, hay definiciones débiles y definiciones fuertes. No se me escapa que esta expresión, "definición fuerte," puede parecer una contradicción terminológica, sobre todo en el análisis del postmodernismo. Pero si la aceptamos, siquiera por su valor heurístico, podremos decir que a medida que nos desplazamos de la acepción fuerte a la acepción débil (otros lo llaman "discurso profundo" frente a "discurso aparente" [M 28/2/99]) podemos apreciar el deslizamiento del significante (y aquí me refiero a todas las variantes del término) hacia un vacío que puede ser llenado casi por cualquier significado. He aquí un ejemplo de definición fuerte: "Postmodernidad . . . no es sino volver la espalda a todas las catedrales de la razón humana, cuando ésta se erige en nueva teología. Postmodernidad es aceptar con Bergson y con Einstein nuestra relatividad, nuestra ambigüedad, nuestra fugacidad y la del universo. Instalarse al margen de toda instalación, sabiendo que los siglos son provisionales. Y hacer un poco de música sentado al sol" (M 13/3/98). Y otro más: "La postmodernidad no es, como creyó Tierno Galván y los exégetas de la movida, una moda pasajera, sino el título de un periodo en la historia humana que abate los pilares de la moral, la estética y el pensamiento que fundó la modernidad y que todavía no encuentra otro modo de expresión más firme que el simulacro, la virtualidad y la indiferencia" (P 19/9/99). Hay quien resume el debate de manera global y un tanto maniquea, señalando la "gran contradicción del siglo XX: por un lado, la evidencia de que ha sido uno de los momentos de la cultura más arriesgados, plurales, valientes, intensos y ricos; y, por otro, la amenaza del postmodernismo, es decir, la sensación de que se ha llegado a un callejón sin salida y de que sólo queda la posibilidad de revisar el pasado para salir adelante" (M 14/4/98).

Otras definiciones abordan cuestiones más específicas, como la terminología misma. Así hay quien habla más bien de "esta modernidad en crisis a la que algunos llaman, de un modo . . . restrictivo, "postmodernidad"” (M 21/4/98); o de "la modernidad reflexiva (Giddens) o postmodernidad [que nos ofrece] un presente colonizado por el porvenir" (P 25/7/99). Nuestra época se puede llamar "postmodernidad, postradicional o como se quiera" (V 20/7/99). Para otros el asunto está más claro y "hoy estamos en tiempo de 'postmo- 
dernidad' y sabemos que la historia se escapa al dominio del hombre" (P 1/6/99), y, aunque podamos decir que "[con la caída del muro de Berlín en 1989] adviene la postmodernidad" (P 30/8/99), ésta ya fue presagiada por "Liza Minelli, en Cabaret . . . en los 70, con sus ingenuas uñas moradas" (M 28/9/99). Por lo demás, "la tan denostada postmodernidad puede enorgullecerse de haber acabado con la noción de herejía cultural" (M 30/5/99) pues la podemos definir como "transvaloración de todos los valores" (M 12/4/98), y decir que se caracteriza por su "acomodada palabrería" (P 8/6/99), por su "falsa sobriedad" (M 12/10/98), y porque su "protagonismo" se debe a que es "fotogénica" (M 7/6/98). De manera extrema, un ejemplo del discurso aparente antes aludido podría ser el siguiente: "La sensación de escuchar la voz de Mari Trini en un taxi de Ankara puede aceptarse como la quintaesencia del postmodernismo" (M 14/2/99).

Desde la perspectiva de la indagación filosófica parece que las cosas están un poco más claras. Así, hay "dos corrientes que predominan en los filósofos del siglo XX: la materialista y la postmodernista. 'Los primeros actúan sobre la realidad y los segundos intentan que la realidad se adecúe a su pensamiento teórico"” (V 9/4/99). Sea esto cierto o no, "la filosofía ... debe plantearse cuál ha podido ser su fallo y por qué hoy la razón postmoderna es autodestructiva" (A 7/4/99), y debe estar vigilante ante "esa tendencia del postmodernismo de enterrar la razón ilustrada" (P 28/1/99), y. tener cuidado con "las propuestas 'postmodernas' de disolución de la razón" (V 15/1/99), con "los irracionalismos, los nihilismos, fenómenos de la postmodernidad que quieren matar la gallina de los huevos de oro" pues "existen materias y géneros diferenciados" y "no da todo lo mismo" (A 21/2/99).

Pero afortunadamente "la postmodernidad ha tocado fondo. Nos acercamos a un nuevo siglo" en el que "vuelve a dársele importancia a la razón y al lenguaje como reflejo del mundo" (A 6/4/99), de manera que se podrán superar "los cuentecillos postmodernos urdidos sobre la fragmentación textual y la dispersa narratividad, o la transfusión de géneros de lo Existente" (M 1/9/98); "liquidadas las utopías a precio de saldo, muchos de los intelectuales que habían creído en el absolutismo de una perfección social futura optaron por el relativismo o la versión narcisista postmoderna" ( $\mathrm{P}$ 1/5/99), pero, aunque algunos hayan hecho "una transición impoluta del marxismo a la postmodernidad" (P 2/8/99), "muertos trágicamente Foucault, Deleuze, Althusser, Roland Barthes, sólo subsisten epígonos sin ningún interés . . que asociamos a las aventuras (o mejor desventuras) postmodernas" (M 11/12/98). Pero queda también otra esperanza. "Alejandro Llano, catedrático de Metafísica de la Universidad de Navarra, propuso 'una nueva manera de pensar' que permita superar el punto muerto de la postmodernidad [pasando] del racionalista 'paradigma de la certeza' al 'paradigma de la verdad'" (A 13/1/99).

El paradigma de la verdad sin duda evoca la capacidad de la religión para crear mitos y narrativizar explicaciones del mundo, de este y del otro. La religión predominante, es decir, la más verdadera, en Occidente es la cristiana y así no extraña la crítica desde esa perspectiva a la omnipresencia, no de Dios, sino de lo postmoderno. Algunos se preguntan qué "adjetivo le colgaría la postmodernidad [al obispo Pere Casaldáliga] ¿Santón? ¿Iluminado?" (V 26/2/99); otros lamentan que "desaparecida la sanción religiosa que antaño persuadía . . . a obrar de cierto modo correcto, los agnósticos postmodernos no [hayan] logrado 
consensuar un código de valores" (A 7/2/99); y el Papa tampoco nos falla esta vez cuando en una encíclica "condena la postmodernidad como sistema filosófico que propugna "la carencia total de sentido' y apuesta por 'lo provisional y fugaz"' (M 16/10/98) Y ello, tal vez, a causa de "la publicación reciente de tres 'nuevas' biblias: la laica, la cultural y la postmoderna" (P 26/1/99). Pero no sólo la religión católica se ve afectada. Ya en tiempos, Hussein de Jordania tuvo que hacer un gran esfuerzo para "acabar con los palestinos y con su herejía de un islam postmoderno" (P 11/2/99).

Otro discurso fuerte, a priori, es el de la ciencia. Pero ese discurso ha degenerado también en el de la "ciencia contemporánea y postmoderna" que nos dice que "todo está interconectado" (M 8/1/99), y sin duda resulta llamativo el tratamiento "postmoderno" de Plutón y la enternecedora defensa de su carácter de planeta excéntrico y marginal. (M 3/2/99). Esa "ciencia postmoderna" es criticada desde dos perspectivas: en primer lugar, por el uso inapropiado de la jerga científica. Así, "[Jean] Bricmont argumenta sus críticas" contra "los denominados filósofos postmodernos franceses (Lacan, Deleuze, Baudrillard, Kristeva)" (M 30/5/98); y Alan Sokal, a la vista de cómo "todos quedaban impresionados por la fantasía postmoderna," por "la verborrea relativista postmoderna . . . decidió escribir un artículo ... empleando el mismo lenguaje de los postmodernos [tratando de demostrar] que todo, incluso la Física, era un producto cultural. Aquello causaría un orgasmo entre los postmodernos." En la reseña se menciona que "Sokal dará una conferencia . . . que promete echar aún más gasolina al fuego postmoderno" (M 22/4/99), con lo cual somos todos, metafóricamente, condenados a las llamas del infierno. La "impagable labor" de Sokal y Bricmont ha consistido en desvelar "crudamente los errores seudocientíficos de muchos pensadores de moda que se han dado en llamar postmodernos, pero no hacen sino admirar con su ignorancia a otros ignorantes" (P 6/8/99). Que esto lo escriba un especialista en mitología cristiana, no deja de ser irónico, dado que para algunos hay discursos que no se hallan tan alejados los unos de los otros. Pues es en ese contexto en el que, por otro lado, se critica a esa "ciencia postmoderna" por su supuesta negación de la objetividad de la ciencia "convencional." Así, el Manifiesto Humanista 2000, firmado también por Vargas Llosa, "lamenta la influencia persistente del pensamiento anticientífico, antimoderno, incluido el del fundamentalismo religioso, y del postmodernismo, una doctrina que niega toda objetividad a la ciencia y sataniza con frecuencia la tecnología" (P 2/9/99).

En el campo de la arquitectura la alusión a la postmodernidad suele tener una función descriptiva muy específica. Así, se nos habla de los arquitectos Rafael Moneo y Ramón Bescos, quienes inauguran "la sensibilidad postmoderna" (M 30/1/99) "con el Bankinter" (P 29/1/99) abriendo "el camino a la postmodernidad que quería volver a dialogar con la ciudad existente" (M 16/5/98). Lo postmoderno genera un variado catálogo: los "bajos de Azca-Orense-Capitán Haya, una franja del Madrid postmoderno" (M 15/3/99); el ayuntamiento de Torrelaguna que "ahora presenta una reforma interior postmoderna" (M 23/8/98); el proyecto de "coronar las dos torres [de Notre Dame] con . . . dos enormes pirámides en forma de agujas postmodernas" (P 7/3/99); o el Palacio de Congresos y de la Música Euskalduna que "sirve . . . de contrapunto a los excesos postmodernistas de la imaginación de Frank Gehry [en el Museo Guggenheim]” (M 20/2/99). 
Hay arquitectura postmodernista porque hay arquitectos como Zaha Hadid, que "se ha formado en los últimos 20 años en el postmodernismo y el deconstructivismo" (P 16/7/99), o como Michael Graves, "uno de los adalides del postmodernismo." Aunque él no se sienta cómodo si se le ubica en la arquitectura postmoderna— "Prefiero que me llame arquitecto, sin etiquetas" (V 23/2/99)—y aunque ahora se le considere un "postmoderno devaluado," es el autor de "uno de los manifiestos postmodernos: el Ayuntamiento de Portland," y de él se dice que "dejó de ser moderno para ser declaradamente postmoderno" (P 23/2/99), un lenguaje que parece utilizarse como el equivalente en arquitectura de la expresión "salir del armario." Pero ahora "el decorativismo de la arquitectura postmoderna está totalmente desprestigiado y superado" (P 23/2/99) como prueba el hecho de que "los cambios estilísticos marcados por el postmodernismo, el eclecticismo o el deconstructivismo, apenas han dejado huella en los distintos jurados [de los premio FAD de Arquitectura]" (M 30/6/99).

Las ciudades, por acción u omisión de los arquitectos o de los políticos, acaban adquiriendo también esa cualidad postmoderna. En general, "en una ciudad postmoderna de derechas el espacio privado es excelente y el espacio público está abandonado" (P 7/6/99). Esa interrelación entre la ciudad y la política quizás explique por qué "Pujol ha sido radicalmente incapaz de generar nada en el campo de liza de la cultura moderna y postmoderna" y que haya dos realidades que no ha podido controlar, "una es Barcelona como ciudad; otra es el mundo artístico e intelectual moderno y postmoderno barcelonés" (M 30/4/98); y explique por qué "el Madrid de la postmodernidad" ya no está "simbolizado por el sainete, el cheli, la chulería, el bombón, el mantón, el chotis, etc. . ." (M 20/6/98). Desde un punto de vista diferente Gianni Vattimo es contundente al señalar que "Roma fue postmoderna. . . . Segundona pero, eso sí, postmoderna. . . . Una amalgama de ideas que . . . representa . . . el primer intento de cosmopolitismo, tolerancia y, por ende, de postmodernidad. . . . Roma es la postmodernidad . . . la cuna de la postmodernidad [en la que] todo está sujeto a las diferentes interpretaciones, a la hermenéutica" (V 26/2/99).

En el campo de la danza las alusiones a lo postmoderno son descriptivas más que valorativas y se refieren esencialmente a "Merce Cunningham . . . padre de la danza postmoderna [que surge] durante los años sesenta . . como rechazo de los cánones de una sociedad materialista y de la guerra de Vietnam [e] irrumpe en Europa centrándose sobre todo en Francia" (V 4/2/99); y a cómo "Cunningham y [John] Cage . . . crearon . . . el auténtico cimiento estético de la era postmoderna en el baile" (M 21/7/99). Pero en el mundo del arte, sobre todo pictórico, lo postmoderno es una cualidad de algunos artistas como "Olinski [que] fue ... uno de los grandes maestros de la abstracción postmoderna" (M 8/5/99), o algo que ya forma parte de la cultura establecida de manera que "[el objetivo del nuevo director del Guggenheim de Nueva York] es extender los cánones del arte, impactar en audiencias más diversas y mantenerse a la vanguardia de una cultura postmoderna altamente estimulante" (V 22/1/99). Otros certifican la normalización postmoderna mediante "dos o tres exposiciones temporales ... entre las cuales ya se está trabajando en una titulada 'El laberinto postmoderno,' comisariada por Charles Jencks" (V 10/3/99); mediante publicaciones como "Art of the Postmodern Era . . ." un libro de Irving Sandler (V 17/3/99); o, como Jorge Galindo, mediante el "uso atrevido de soportes poco habituales y 
una temática fantásticamente escabrosa ... [para conseguir] una especie de heterodoxa versión postmoderna de El jardín de las delicias" (M 10/4/99).

Sin embargo, "el artista de los $80 \ldots$. en términos postmodernistas es alguien, sobre todo, cómplice con el sistema" (M 27/3/98). Pero afortunadamente es posible encontrar un atisbo de pureza, como el alfarero Jeroni Ginard sobre el cual nos dice Miquel Barceló: "Me gusta porque él no es un postmoderno ni ha reencontrado el oficio; sigue la tradición con auténtica naturalidad" (P 22/6/99). Y podemos rechazar ciertas ideas preconcebidas y refutar que "'la ironía y la distanciación sean un invento del postmodernismo.' O que tal movimiento marque el fin de las vanguardias: 'La modernidad resiste,"' apunta alguien como mensaje de esperanza (V 8/7/99).

En el campo de la literatura nos encontramos con un catálogo de nombres que aparecen asociados de diversas formas con la postmodernidad. Por ejemplo, "Borges propone una disolución del yo," una reflexión que es "precedente de lo que viene después de la postmodernidad." Igualmente, "su relación lúdica puede ser indicio del postmodernismo" (P 15/3/99). En un sentido fuerte se comenta que "la obra de [Eduardo] Mendoza" constituye un "paradigma de la novela postmoderna" (A 7/1/99). Por su parte, el novelista "[Javier] González no recurre al minimalismo, ni al llamado "realismo sucio"" y el crítico se pregunta: "¿dónde para aquella corriente de alcantarilla que daba la impresión de haber descubierto la panacea de la postmodernidad?" (V 5/2/99). Otros, en su línea de siempre, aparecen en un contexto más polémico. Así a Javier Marías se le tacha de ser "el niño mimado y solitario y encaramado de la postmodernidad" que "se hace una paja, con sus propios muñecos" (M 20/5/98). Otro novelista, José Luis de Juan, habla así de su propia obra: "No creo en la escritura lineal. Mi novela puede ser postmoderna," para añadir sin reparos: "Es infinitamente más provechoso leer a los griegos que a cualquier novelista de hoy agasajado por la crítica" (P 27/4/99). Y a fe que dan ganas de hacerle caso y no leer ninguna de sus novelas. Del poeta y ensayista [Michel] Houellebecq se dice que "perpetra una novela rebosante de agilidad y postmodernidad" (V 22/1/99); de Pablo Neruda que "empezó en el postmodernismo romántico" (M 23/9/98), un uso tal vez muy específico del término, y de Jaime Siles que su poesía "es postmoderna" (P 26/6/99).

Pero de nuevo en este campo la postmodernidad parece ejercer una influencia perniciosa de diferentes maneras. Así, "si Fanny [Rubio] fuera más postmoderna y más sensible a los arrullos del comercio hubiera optado por otro [título para su libro]" (M 21/6/98). Se señala también que "los postmodernos tienen relegado a Miguel Hernández en las caballerizas" (M 21/6/98) y que "[la poesía de Baudelaire] hoy sonará a vacua retórica a los que sólo sean capaces de percibir el eco de su postmoderna vacuidad" (M 7/6/99); "la obra [de Peter Handke sobre Serbia] es "una mezcla de antimoral postmoderna y misticismo reaccionario"” (P 10/6/99), pero afortunadamente nos queda "[Günter Grass], un ejemplo militante de autor contrario a la postmodernidad" (M 3/6/99); y "ahora que al fin parece remitir la pasión postmoderna por lo falso y lo fragmentario, es cuando mejor podemos apreciar el testimonio de [la obra de Goethe que buscaba lo exacto y verdadero para así recibir alivio frente al caos]" (M 23/8/99), aunque hay quien se pregunta: "¿Alguien pretende, en un 
experimento literario, que los perros escriban novelas postmodernas a base de tomar prozac?" (M 16/12/98).

Ese efecto pernicioso afecta a algunos autores que "han buscado las recompensas que aguardan, desde la eclosión de la postmodernidad, a quienes ofrecen mero entretenimiento barnizado con alguna capa de transcendencia" (M 13/9/98); en algún caso, como El Aleph de Borges, "la fama universal de este libro de relatos fantásticos . . . desmiente la vacua superstición de los editores postmodernos en contra de un género que algunos llegan incluso a considerar maldito" (M 20/8/99); y alcanza incluso a "Pepe Carvalho . . . ex agente de la CIA, ex prisionero político, ex comunista, en fin, un personaje postmoderno a la conquista de la globalización” (M 5/10/98).

En música "se puede hablar de una tendencia impresionista, postimpresionista, romántica, vanguardista, modernista e incluso postmodernista" (A 6/8/99), y hay ejemplos como "Alfred Schnittke, el compositor total ... y postmoderno [que] se distancia de [Shostakovich] y deriva a una suerte de territorio estético postmoderno [que se define por conceptos como] misticismo, búsqueda de las raíces musicales, talento comercial, pluralidad estilística, eclecticismo" (M 5/8/98). En paralelo con la filosofía, "[la música del siglo XX] ha experimentado, de modo quizás más traumático que en otras artes, el desengaño y la desilusión postmodernas" (M 15/7/98). Pero mientras la ópera Carmen se beneficia de la contribución del "modisto Jesús del Pozo como artífice de un vestuario postmoderno" (V 7/4/99), no se puede decir lo mismo sobre "los participantes en el gratuito Gazztejazz, [quienes] palidecieron un tanto, dejando al descubierto los tics programáticos y algo postmodernistas de la selección artística" (M 26/7/99).

La música popular también hace variado uso de lo postmoderno. Así a Jordi Clausell se le tilda de "rockero postmoderno" por la edad (V 7/5/99), mientras "Martirio se ha convertido en la tonadillera más postmoderna de la época" (M 11/5/99) y en un totum revolutum "adolescentes, postmodernos y proletarios se sienten hermanados alrededor de Guildo, [representante alemán en Eurovisión], y su grupo, los Calcetines Ortopédicos" (M 6/5/98).

El cine constituye un campo de batalla cultural en la que el espectador, que sólo cree que está viendo una película, en realidad asiste de manera inconsciente a un capítulo más de una guerra interminable entre los que hacen "cine de verdad" y un grupo de postmodernos infiltrados. Se trata de una lucha, sorda y cruel, que no ha pasado desapercibida a las sagaces mentes y la perspicaz mirada de los críticos de cine, sobre todo de El País y El Mundo. Aunque haya excepciones, como "[James Marsh,] un cineasta al cual la etiqueta de postmoderno no añade, por una vez, un matiz peyorativo" (P 19/9/99), el tono suele ser predominantemente negativo, sobre todo si se compara con ilustres antecedentes. Así, "[la cámara de Hitchcock] voló sobre el plató mucho antes de que nos llegara el aluvión postmoderno actual, gratuito y puramente técnico, salvo en contadas ocasiones" (M 2/5/99). Afortunadamente "Lars von Trier con su reciente filme Los idiotas [hace] una propuesta de radicalidad estética y moral que podría resumirse bienintencionadamente como un sincero intento de eliminar todo lo superfluo que el lenguaje cinematográfico ha ido acumulando en estas últimas décadas digitales y postmodernas" (M 12/3/99). Algo que tuvo su contrapartida en la conocida "Corrupción en Miami ... un referente del pastiche postmoderno" (M 12/1/99). 
Pero el problema no es lo malo que es el cine postmoderno sino que de las conspiraciones judeo-masónicas hemos pasado a las postmodernas, y así "nuestros queridos postmodernos rechazarán por doctrinaria convicción ... que El resplandor" sea considerada "una obra mayor" (M 17/3/99). Pero no todos están de acuerdo con respecto a Kubrick. Así, junto a una caricatura del cineasta podemos leer: "La postmodernidad consiste en más cámaras y nuevos encuadres para la misma vieja mierda" (P 4/9/99). Hay además "[dos cineastas] chinos postmodernos" con "prestigios absurdos, [y] ambos igual de plastas" (M 25/5/98); y está "Jane Campion [quien] todavía no ha conseguido o no ha querido despojarse de sus jodidos manierismos y amaneramientos postmodernos" (M 5/9/99). Así, no es de extrañar que en las crónicas sobre los festivales de cine no sólo se nos informe sino sobre todo se nos ponga en guardia. Por ejemplo: "Concursó también Ocho mujeres y media, nuevo camino a niguna parte del británico Peter Greenaway, que va de postmoderno audaz y sigue empeñado en hacer antiguallas de cine pictórico capaces de aburrir a las piedras. Pero hay que tener en cuenta que este año preside el jurado David Cronenberg, al que puede darle por ejercer su modernidad y sacar tajada para alguno de los bodrios de sus correligionarios con ínfulas de estética feísta y . . . rompedora" (P 23/5/99). La defensa de ciertas posturas, esperemos que estéticas, produce a veces deslizamientos un tanto sorprendentes. Así, en una crónica sobre el Festival de Venecia en su edición de 1998, al hilo de un comentario sobre la película alemana Lola corre, se señala que "hay razones para echarse a temblar" porque en el jurado del certamen "está metida (sic) la postmoderna californiana Kathryn Bigelow." El crítico no aclara si sus temores se deben a que sea mujer, a que sea californiana, a que sea postmoderna, o a la peligrosa combinación de todo ello. Pero lo que llama la atención es la solución (para el debate) final que el crítico propone y que consiste literalmente en que "el presidente del jurado, el cineasta Ettore Scola, descargue un puñetazo de orden."

$\mathrm{Al}$ parecer "uno de los problemas radicales con que vamos a estrenar el tercer milenio" es "la crisis de la política postmoderna" (V 7/1/99). En nuestro caso "cuando terminaban los años setenta, queríamos ser muy de nuestro pueblo a la vez que muy europeos, recuperar la tradición local y parecer postmodernos" (P 13/6/99), y ahora podemos decir que España ya no "huele a pueblo," y no sólo va bien sino que "ha empezado a ser otra cosa: social, socialista, moderna, postmoderna, europea y progresista" (M 24/3/99). Ello es, en parte, gracias a que tenemos un "socialismo postmoderno" (M 26/3/98), y a que en vez de enfrentamiento entre las dos Españas de siempre lo que queda es "esa piscina común del agua democrática clorada con tolerancia, incredulidad y unas gotas de anémica y desvalorizada postmodernidad" (M 8/6/99).

Con "nuestra mente de homínidos postmodernos" (M 8/9/98) que rechazan la guerra sucia, "los ciudadanos de la España postmoderna están resignados a tragar con tal de que se acabe la violencia [de ETA]" (P 12/6/99), que como es sabido reclama algo diferente al "nacionalismo" como "identidad postmoderna polivalente" que propone Xavier Rubert de Ventós (P 10/7/99). La negación de la cultura española es parte de unos "episodios nacionales-nacionalistas . . . tan atávicos y tan postmodernos de "nuestra España"” (A 31/3/99). Pero, en cambio, la Constitución es sagrada y no es conveniente que esté expuesta a ciertos juegos postmodernos. Y es que el dilema es muy simple: "Algunos hablan de Constitución 
como tabla de salvación; otros hablan de ella como una sustancia indefinidamente moldeable, donde todo cabe. Según esto, habríamos alcanzado el cénit de la postmodernidad política; el predominio absoluto, si así puede decirse, de la relatividad y la levedad; lo mismo podemos hacer un rinoceronte que una catedral gótica; maravillas de las lecturas múltiples, como si la lectura diera todo o nada, o pudiera atribuir al significante Constitución cualquier significado, o sea la ausencia total de significado" (P 13/5/99).

Más específicamente, nuestros partidos políticos se han visto teñidos por este signo de los tiempos. Dónde situarse políticamente tiene importancia, porque "el centro es . . eso: ausencia de problemas. . . . En el fondo, es la negación de la política. En la forma, es una máscara, un camuflaje. . . . Pero es lo que se lleva hoy, en pleno postmodernismo" (A 31/1/99). De ahí que no resulte extraño que "el PP . . . más que centrista, suele resultar postmoderno. . . . A este tipo de partido" con adelgazamiento ideológico y engordamiento del liderazgo "se le denomina 'postmoderno,' 'profesional-electoral' o 'mínimo'. . . . El problema ahora es que el PP resulta demasiado postmoderno" (P 30/1/99). Y así el PP celebró "ese congreso postmoderno del recinto ferial donde las cámaras de televisión se mueven en vuelos rasantes" (V 31/1/99), para incluir a todo el mundo "gente muy variopinta, desde los postmodernos de centro hasta la derecha de la España eterna" (V 2/2/99).

Algunos políticos del PP aparecen relacionados con lo postmoderno. Así, “Abel Matutes llega al hall postmoderno del Salón de Columnas" (M 7/4/99); y "Alvarez Cascos ... se dedica . . . a las ciencias sociales desde la perspectiva de un filósofo de la historia dotado de una cosmogonía postmoderna en lo universal" (P 25/1/99). Pero quien en este apecto se lleva la palma es "Isabel Tocino, a la que no perdonan la melena rubiasca, la zamarra de pastora de la transhumancia y la piel negra de motera postmoderna" (A 18/1/99). Y sin duda es imposible no ver a esta ministra como la más postmoderna, dado el carácter contradictorio de su imagen pública: Opus, pero con una pose sexy en su despacho; ministra de Medio Ambiente que visita las cañadas vestida de pastorcita, pero también acude a una reunión motera hippy en la que de nuevo aparece con una pose típicamente provocativa que parece decir "ven y monta en mí," aunque no queda muy claro si el mensaje lo transmite la moto o el lado oscuro de la ministra. Así, Tocino se convierte en un puro significante dado que los diferentes aspectos que la componen hacen inviable la producción de ningún significado preponderante ya que todos se anulan entre sí.

En otros partidos también se observan estas influencias. El Partido Comunista es "ese Hamlet postmoderno" (P 27/6/99) (viéndose de nuevo aquí, como en otras cosas, una sutil coincidencia entre políticos tan diferentes), y ERC se declara en contra del "caciquismo rural de CiU y contra el caciquismo urbano postmoderno del tándem PSC-IC” (V 14/1/99).

En el plano de la política internacional hay que señalar que "Europa es ligera, postmoderna y deconstructiva" (M 3/4/98); que "el zapatismo replantea la modernidad, retomada tras el obsoleto interregno postmoderno, una travesía del desierto falsificado por el skyline de Las Vegas" (P 15/2/99); y que "los juegos malabares de la postmodernidad [no] tendrán efectos inmediatos [en el conflicto del Ulster]" (M 13/4/98). En Israel la "economía salvaje de libre mercado" produce "una visión del mundo que, consciente o inconscientemente, se ve reforzada con ciertas concepciones postmodernas en el ámbito de la izquierda" (P 
12/1/99) Y si "la revolución [portuguesa], un cuarto de siglo después, se volvió postmoderna" (M 26/4/99), en otra revolución, "Castro pretende que su delfín no sea un joven de fines del siglo XX, posterior a la caída del muro de Berlín, postmoderno, postmarxista, e imbuido por las ideas de su tiempo" (V 20/9/99), un raro ejemplo donde el significante parece tener connotaciones positivas.

La reciente guerra de Kosovo también ha resultado ser un suceso explicable en el contexto de la postmodernidad. No ha sido en absoluto un efecto de las políticas fuertes y expansionistas de algún país europeo. Más bien, "la guerra de los Balcanes es inseparable de la negligencia postmodernista de los intelectuales de los años 80" (M 23/4/99). El aspecto material de la guerra también es importante ya que "las guerras postmodernas sirven para probar armamento que, de no haberlas, quedaría obsoleto en los almacenes de juguetería bélica" (P 29/3/99), y "los aliados occidentales . . . se han dejado cegar por la ilusión . . . de que es posible una guerra postmoderna, o 'políticamente correcta,' como algunos la llaman” (P 24/5/99). Para las víctimas de la guerra, la confusión puede ser total. Así, un profesor universitario serbio que había sufrido varios bombardeos en diferentes guerras a lo largo de su vida, señala que "en 1999 todo es postmoderno: no sé cómo calificar a aquéllos que me bombardean ahora" (P 17/5/99). Aunque "en la postmodernidad, el desenlace de una guerra depende también del pensamiento colectivo, de las minorías, de la opinión pública, de las encuestas, de la vigilancia y la crítica de los periódicos" (M 12/5/99), la crítica intelectual puede ser sospechosa pues "no es el bombardeo de [Kosovo], sino el genocidio la cosa que más merece una condena pública unánime. Pero en nuestra sociedad postmoderna, todo vale" (M 18/4/99).

Si tenemos alguna afición deportiva, como el fútbol por ejemplo, debemos saber que "los africanos [son los] ídolos del domingo en la postmodernidad" (M 13/6/98), y hay quien se siente "arrastrado por la vorágine de la incertidumbre postmoderna, fascinado por la mundialización del fútbol” (M 17/6/98). Contándonos las hazañas de estos ídolos están algunos "aprendices de comentaristas [de fútbol que] deberían fijarse en la dialéctica ... del original y postmoderno Arsenio Iglesias" (M 10/7/98). En el mundo del baloncesto también se percibe la infiltración postmoderna y alguien se pregunta: “¿Cómo no rendirse ante los Lakers de Shaquille O'Neal y de Kobe Bryant? Pues porque nos sigue pareciendo un equipo de autistas. Eso sí: muy postmodernos y con muchas facultades. Pero autistas" (M 6/2/99). Menos mal que alguien resiste y que el ciclismo aún no ha sucumbido. En el ciclista hallamos una "lucha minuciosa por la superación, contra el dolor, fraguando la capacidad de resistencia, la dosificación, la voluntad, el aguante, la perseverancia. Son todas estas categorías escasamente postmodernas, nada actuales. Hoy se busca el truco, el atajo y el deslumbre como formas de alcanzar el objetivo que concite el reconocimiento y la gloria" (M 14/9/99).

En cambio, si nuestra inclinación es hacia la llamada fiesta nacional hemos de saber que "se inventa, se fabrica el toro comercial, para que pueda ser rentable esa nueva estética, mal interpretada por una mayoría de toreros postmodernos, que engañan con el toro y con el toreo que realizan cada tarde, desvirtuando la autenticidad del toreo mismo y de todas las suertes" (M 6/6/98). 
En más de un momento a uno le asalta la sospecha de que, efectivamente, lo postmoderno en realidad no existe, de que siempre se trata de una versión de otra cosa, de una copia matizada de un original. Así, comenzando por campos culturales en los que lo postmoderno es una tendencia reconocida, se dice que "el Guggenheim de Bilbao podría parecer una evocación postmoderna de El acorazado Potemkin en sus imágenes más sugerentes" (V 25/3/99); en la danza, "la joven bailarina [Ivana Baresic, en una coreografía de Maurice Béjart sobre Don Quijote, es], alta y delgada como una Dulcinea postmoderna" (M 28/5/99); mientras que "con [el compositor Mauricio Sotelo y el libretista Peter Mussbach] volvemos un poco . . . al esquema Mozart-Da Ponte, aunque en clave postmoderna" (P 19/4/99).

La política también se llena de versiones. En un spot de propaganda en la últimas elecciones "aparece en pantalla un joven de aspecto desaliñado pero apuesto y atractivo (o sea, la versión postmoderna del progre)" (A 29/5/99). Si se habla de la pérdida de votos por el asunto del GAL, se dice que "esa es una forma muy postmoderna de hacer análisis: discurren en función de las pérdidas o de las ganancias" (M 25/7/98); y está "esa versión postmoderna de augures y arúspices que son los encuestadores y técnicos de opinión" (A $3 / 3 / 99$ ), algo que no resulta sorprendente si se tiene en cuenta que en esta sociedad "el terapeuta se ha convertido en el nuevo mago de la tribu y el analista en la versión postmoderna del confesor" (A 10/3/99). Y si se establece un paralelismo entre Antonio Pérez y Felipe II por un lado, y la corrupción del tardofelipismo por otro, se puede observar "la postmodernidad del caso, además de corrupción y crimen de Estado hubo un choque de Madrid con las nacionalidades y reinos" (M 28/3/98). A nivel internacional, y a propósito de la guerra en Kosovo, "la CNN es una adaptación postmoderna de la constatación de Nebrija de que siempre fue la lengua compañera del imperio" (P 24/4/99). Y el lenguaje mismo puede ser excusa para juegos insospechados. Por ello, "justo será . . . despenalizar el asalto a los bancos, sobre todo si le damos la consabida grafía ácrata y postmoderna: el atrako" (P 9/3/99). (Y nos preguntamos si se podría esto aplicar a Médiko de Familia). Pero si lo que necesita es un restaurante, acérquese a "El Bulli en la Costa Brava . . . lugar de peregrinación mundial, equivalente postmoderno de Roma o Santiago de Compostela" (P 25/3/99). Y no deje de apreciar cómo, en alusión a la novela homónima de Juan Goytisolo, "Gil y Gil [se ha convertido] en una especie de Don Julián postmoderno que abriera las puertas de España al moro Muza" (P 16/8/99).

No sorprenderá a nadie que lo postmoderno forme parte de lo que en términos generales se llama la vida cotidiana, cajón de sastre donde confluyen todo tipo actividades y facetas que no queremos encuadrar en ninguna otra categoría. De ahí lo heterogéneo de la descripción que sigue y que recoge referencias a diversos aspectos, como lo arquitectónico: "En un futuro no muy lejano un solo recinto acogerá cines y restaurantes, tiendas de ropa y de libros, en el summum de lo postmoderno, incierta época en que ediciones baratas de obras de Shakespeare pueden llegar a convivir en el mismo 'stand' de oportunidades con bikinis de la temporada pasada" (V 4/4/99); lo culinario: "En España la transformación del hambre y la sed en placer, en cultura, en política, en negocio, es postmoderna; coincide con la década del pelotazo. . . . [L]a transformación del hambre en placer . . . tiene su resplandor en la postmodernidad española" (M 1/5/99); la salud: "esa gripe postmoderna que te pone a 40 
grados de fiebre durante 10 días" (P 20/1/99); los libros de auto-ayuda o que "invitan a enfrentarse con sentido del humor a los postmodernos desastres cotidianos" (P 14/8/99); o las comodidades de la vida moderna: "en [las] dependencias [del Club de Corresponsales de Prensa de Phnom Penh no hay] aire acondicionado—esa maldición postmoderna de los trópicos" (M 22/8/98).

Como elementos presentes en la vida cotidiana, los animales de compañía son también un signo de postmodernidad. El perro "en España ha sido animal rural, hasta un postmodernismo en el que los urbanitas . . consideran de buen gusto poseer una cría de cocodrilo, un mandril, una llama como Chencho Arias . . o todo un zoo como el truculento abogado Rodríguez Menéndez, sin que al diplomático le moleste la tan lejana relación con el abogado" (M 29/7/99). Y ciertas tendencias de la economía neoliberal, como despedir a las personas de más de cuarenta años, no son más que un correlato objetivo de un germen anterior, de manera que "ahora a la tensión por renovar los objetos, los vestidos, los ambientes, se añade la ansiedad por sustituir a los seres humanos que se tienen. El incremento divorcista de los países más industrializados fue sólo la manifestación artesanal de esta práctica postmoderna" (P 26/6/99). Y también las personas concretas se impregnan de postmodernidad. Así "Sara [Montiel] es post/antigua, postmoderna" (M 15/3/98), y se señala el mérito de Isabel Preysler de "casar a su Chábeli con ese escritor postmoderno cargado de talento que es Ricardo Bofill Jr." (P 8/8/99), quien además es "prototipo de latin lover postmoderno" (M 4/8/98).

Las alusiones a la mujer también pueden encuadrarse en diferentes categorías. Así "Lipovetsky prosigue en su desmenuzamiento de las intrigas postmodernas" (P 13/1/99) en la "cuarta entrega de su trayecto sociológico por la postmodernidad," y su estudio La tercera mujer "encarna la manera postmoderna de cambiar las relaciones entre los sexos sin hacer tabla rasa del pasado" (A 13/1/99). Pero la mujer también es usada por la publicidad y así, en relación con el anuncio de un producto anti-estreñimiento donde aparece una mujer sentada en la taza del wáter con las bragas por debajo de la rodilla, se señala que "este es el drama de la publicidad, que es un drama muy postmoderno, tener que encarar la realidad fuerte ... desde el pensamiento débil, lo desagradable desde lo agradable" (M 26/1/99). Se señala la ingenuidad de las "chicas postmodernas . . que creen ser las primeras en haberle llamado culo al culo" (P 11/5/99), y otros directamente contemplan a la mujer en su desnudez, indicando que "lo más prominente de esa zona de las niñas postmodernas son los huesos de la pelvis" (A 11/3/99) y que "la postmodernidad nos ha traído la desmitificación del glorioso culo femenino pero eso no debe convertirnos en coleccionistas de culos, sino en hombres libres" (M 27/3/98).

Cuando se intenta definir lo postmoderno a veces se generan descripciones con las que el objeto no se identifica, y en ocasiones el adjetivo postmoderno se plantea como un insulto, algo que llamar a alguien, algo con quien calificar/descalificar a alguien, de la misma manera que "maricón" no expresa, para el que habla, una opción sexual sino una condición abyecta. Según refería un alumno de una Facultad de Arquitectura, allí se ha llegado a una simbiosis perfecta y se habla de ciertos edificios como "mariconadas postmodernas." Y si podemos insultar a un edificio, mucho más podremos hacerlo con las personas, con cual- 
quier excusa. Por ejemplo, uno no debe perder el tiempo con la ciencia, la filosofía o el cine porque "personas como Tip son mucho más imprescindibles para el mundo que científicos postmodernos, filósofos alemanes, cineastas chinos y demás pelmazos profesionales" (M 9/2/99); en especial "los filósofos postmodernos, los ligeros y los pesados escriben a salto de mata" (M 22/3/98), y adolecen de "la flojera del pensamiento postmoderno" (V 15/1/99). Y ello es más peligroso aún en el marco de las universidades de verano donde "es normal que uno encuentre junto a profesores y estudiantes serios, auténticas gachupinadas, carnavales disfrazados, ferias de postmodernos cabreados, oficiantes irrisorios embromados en liturgias de charlas de café, etcétera" (P 1/8/99). Parece lógico en este contexto que en Cornualles la única región de Inglaterra "donde el eclipse será total, se [haya] proclamado el estado de alerta en espera de una invasión de nómadas 'New Age' y de hippies postmodernos" (A 11/8/99), pues después de todo "el hombre postmoderno es desapasionado, desmemoriado y un poco tonto" (M 5/5/98), y la sustitución de los tontos de pueblo "por los famosos indica que los famosos son tontos de pueblo postmodernos-icybertontos?" (P 25/8/99).

Si es verdad que la publicidad tiene esa capacidad para expresar el drama postmoderno, podríamos preguntarnos por la razón de todo esto: ¿será el café? Lo que parece claro es que si la tendencia de este tipo de descripciones continúa uno puede imaginar que en un futuro cercano veamos a gente en los programas de auto-denuncia dando testimonio de su conducta como postmodernos, y cómo eso les llevó a toda clase de vicios y perdieron sus maridos o esposas, sus hijos, sus amigos, su empleo. Algo, en fin, en la mejor tradición de Jerry Springer. O les oiremos gritar "arrepentíos, el día se acerca." O quizás debamos reescribir un viejo lema de la profesión periodística en los siguientes términos: "No le digas a mi madre que escribo sobre la postmodernidad, dile que soy pianista en un burdel." Al final uno se encamina en la oscuridad hacia un garito donde te espera un grupo de personas sentadas en círculo que te saludan por tu nombre tras haber pronunciado las palabras rituales: "Hola, me llamo Manolo y soy un postmoderno." Pero si esa figura con gestos clandestinos que se dirige a una reunión de postmodernos anónimos, versión postmoderna de la bestia que dibuja Yeats en "The Second Coming," es un posible final, siquiera onírico y surrealista, también podríamos, al estilo de Jerry Springer, dedicar a esta cuestión "a final thought." Dado que este trabajo puede ser a su vez postmodernista o metafictivo, podemos imaginar un segundo final y preguntarnos, de nuevo citando, con perdón: ¿qué hacer?

Un segundo final propondría una reflexión, más allá de la constatación del estado de cosas, e implicaría una invitación a preguntarse por qué en este país (como en otros, tal vez) todo lo relativo a la postmodernidad ha sido generalmente tratado con tal nivel de, no ya menosprecio, sino desinformación, desde puntos de vista tan sesgados, tan equivocados y superficiales. Esto último puede proyectar la idea de que se habla desde una posición en la que se sabe exactamente cómo definir este momento cultural, y ello está muy lejos de la intención y de la capacidad del que esto escribe. Se trata más bien de poner de manifiesto la desidia y la pereza intelectual que nos lleva a utilizar el lenguaje de manera frívola, precisamente, y a usar el término "postmodernidad" como una etiqueta que sirve para señalar el esnobismo del sujeto más que para describir el objeto representado, comprobándose una vez más que el uso del término nos define más a nosotros que al mundo "real." 
Como hemos visto en esta muestra de discursos que describen la postmodernidad se puede ir desde las acepciones más estrictas a las más vagas, en un proceso creciente de caotización del significado, hasta el punto en que lo postmoderno se convierte en un significante de articulación totalmente libre. Así, por un lado, encontramos artículos que presentan análisis de inspiración postmoderna con una apreciable base teórica, o artículos que, implícitamente, confirman lo que se postula desde las filas postmodernas; mientras, por otro lado, llama la atención el hecho de que aparezca casi siempre el término "postmoderno" pero no "postmodernista," lo que parece indicar un uso del mismo cercano a una sociología general y difusa más que un uso específico y técnico. Y en ciertos casos hasta se podría decir, no para cerrar, sino para cuadrar el círculo, que se hace un uso "postmoderno" del término postmoderno .

El postmodernismo (y sus variantes) sigue siendo un significante a la búsqueda de sus significados. Por ello, pienso que, por una vez, la Universidad no debería hacer caso a Borges en esa división del trabajo y de los objetos de estudio que propone. Y no se trata de recurrir a la ya conocida idea de que la prensa nos ofrece un conocimiento inútil. Parafraseando otro viejo lema, podríamos argumentar que lo contemporáneo es demasiado importante como para dejárselo a los periodistas. Y en un trabajo de tantas citas termino con otra cita. Como dice Francisco Jarauta, quien a su vez cita el testamento de Deleuze, "el trabajo del intelectual ... no debe ser ya hacer exégesis o mirarse en el retrovisor, sino asumir la intemperie y recorrer el tiempo actual, con todas sus tensiones y sus gritos, para establecer sobre él una serie de conceptos que lo nombren y construyan una cartografía capaz de situarlo" (P 15/9/99). 